\title{
Multiscale characterization of the porous system of carbonate rocks of the Brazilian Pre-salt.
}

Alyne Duarte Vidal'1, Caroline Henrique Dias², Inácio Figueiredo Borges², Lizianne Carvalho Medeiros², Josias José da Silva ${ }^{3}$ Universidade do Estado do Rio de Janeiro', Universidade Federal do Rio de Janeiro², PETREC - Petróleo Pesquisa e Tecnologia ${ }^{3}$

Copyright 2019, SBGf - Sociedade Brasileira de Geofísica

This paper was prepared for presentation during the $16^{\text {th }}$ International Congress of the Brazilian Geophysical Society held in Rio de Janeiro, Brazil, 19-22 August 2019.

Contents of this paper were reviewed by the Technical Committee of the $16^{\text {th }}$ International Congress of the Brazilian Geophysical Society and do not necessarily represent any position of the SBGf, its officers or members. Electronic reproduction or storage of any part of this paper for commercial purposes without the written consent of the Brazilian Geophysical Society is prohibited.

\section{Abstract}

The characterization of the petrophysical properties, especially the elastodynamic properties, makes possible an accurate evaluation of the reservoir minimizing its exploratory risks. The porosity of a reservoir, as well as the distribution and pore size are presented as one of the properties to be considered in a flow analysis of the reservoir. The reservoir rocks, in general, present a great deal of complexity with respect to the porous system, where it is possible to observe different pore sizes ranging from nanometers to millimeters. The present work analyzed, through a multiscale analysis of rock images, the porous system of reservoir rock of Sapinhoá field.

The results showed that the multiscale composition presenting smaller digital porosity values than those measures in the laboratory, this fact may be an indication that the porous fraction consisting of vugular pore size was not included in the volume used in the digital simulation. The multiscalar treatment allowed to describe the complex porous system, in order to understand much of the different pore sizes and porosities that constitute the carbonaceous.

\section{Introduction}

The increasing number of discoveries in recent years and activities related to pre-salt reservoirs have attracted the interest of large oil companies that are interested in investing in this segment in the Brazilian sedimentary basins. Santos Basin is currently one of the main hydrocarbon exploration and production basin in the Brazil, thus receiving large investments in research along the recent years.

The pre-salt reservoirs are compound by carbonate rocks which the variety of textures, directly impacting the petrophysical parameters. That complexity is explained by the large geological heterogeneity generated by the variability of grain forms, different types of pores and propensity to the effects diagenetics. Therefore, for the proper geological characterization, it is essential to integration of rock data, well logs and images.
Petrophysical properties, especially the elastodynamic ones, are influenced by several factors such as composition and mineral arrangement, porosity type, density, degree of cementation, type and saturation of fluids that fill the porous space, besides other factors such as temperature, frequency and amplitude (Dobrin 1976, Thomas 2000, among others). The characterization of these variables is of fundamental importance, since in this way it is possible to understand how they can influence the elastic properties of the rock, thus enabling a better evaluation of the reservoir quality and consequently mitigating the exploratory risks of a sedimentary basin.

According to Lucia (2007), the properties of the reservoirs are controlled by two basic networks of pores composed of intergranular and vugular pores. The effect of vugs on reservoir properties is strongly controlled by the type of interconnection, separate vugs (only through interparticle pore network, if any), and connected vugs (vug-vug direct contact). Lucia (2007) stated that, at a certain scale, all porous space is connected, being the main issue how the pores are connected; therefore, the pore space must be classified based on the rock texture and its petrophysical properties in order to integrate geological and engineering information.

The pore size distribution is extremely important since the physical properties of the rocks depend on the size and shape of the pores, being relevant to the knowledge of the reservoir logs, facilitating the knowledge of the behavior of the oil and gas reservoirs (Kumar, 2005). From the methodology presented by Lucia (2007), Ramakrishnan et al. (2001) recognize three types of qualitatively different porosities that contribute to the total porosity of a carbonate: vugular $(r \geq 100 \mu \mathrm{m})$, intergranular $(r \geq 5 \mu \mathrm{m})$ and intragranular porosity $(r \leq 5 \mu \mathrm{m})$.

The present work aims to a multiscale characterization of the porous system of reservoir rock from Sapinhoá Field, situated in the Santos Basin. In carbonate rocks, in general, the porous system presents a great deal of heterogeneity and multiple porosities, that is, spatial scales of quite different lengths. In order to make the pore space as more representative as possible, the images were acquired with the of $x$-ray microtomography techniques in different volumes of samples.

\section{Method}

The reservoir rocks, in general, present a great deal of complexity with respect to the porous system, where it is possible to observe different pore sizes ranging from nanometers to millimeters. Such complexity cannot adequately represent the entire porous system in a single image, in other words, in a single resolution. Resolution is 
Multiscale characterization of the porous system of carbonate rocks of the Brazilian Pre-salt

defined as the ability of the system to distinguish two adjacent structures, the closer these structures are, more easily they are detected and the better the resolution. On the other hand, for a higher resolution, the smaller it tis the observed region in the sample. Due to this limiting factor of the resolution, an adequate evaluation of the porous system it is necessary to make several acquisitions of images with different resolutions, resulting in images that capture the different possible pore scales.

This work was based on the methodology presented by Fernandes (1994), Papadoulos (2009) and Mantovani (2013) to perform the multiscalar integration of the porous system. These researchers used a mathematical model that enables the multiscalar composition of porosity, pore size distribution. For the analysis, samples from the Brazilian Pre-salt were used, with 7 samples of plug size of 1.5 inches and 7 samples of smaller size, called microplugs. Where th microplugs were extracted from the 1.5-inch plug.

From the same sample, two different images with different resolutions were taken, as shown in Figure 1. The scale 2 is assumed to be contained in the scale 1. In terms of resolution, it is also considered that $r_{2} \ll r_{1}$.

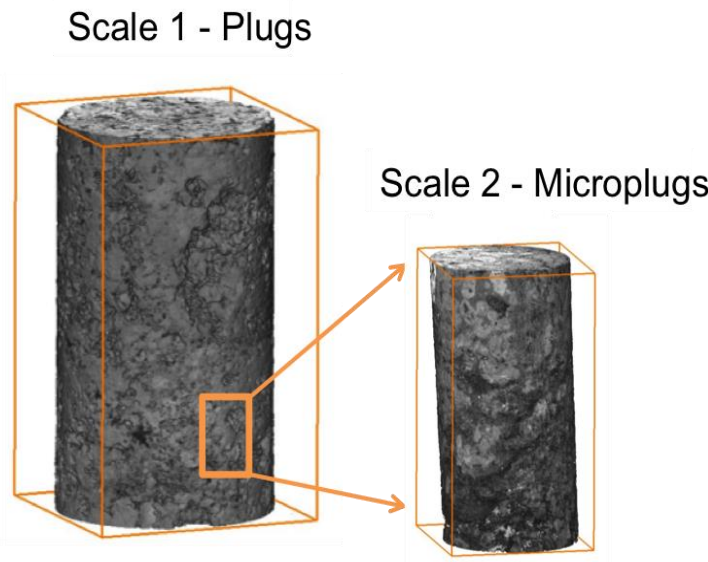

Resolution: 18 microns.

Resolution: 7 microns.

Figure 1 - Schematic representation of the multiscale composition model for two spatial scales.

Taking into account the contribution of the three different scales we can find the total volume analyzed by means of the total volume of scale 1 . The total porosity is given by:

$$
\phi_{T}=\frac{V_{1 P}+V_{2 P}}{V_{i T}}
$$

Where $V_{i P}$ is the pore volume for each scale. Considering the volumetric fraction of pore space is $\phi_{T}=\frac{V_{i P}}{V_{i T}}$ and the volumetric fraction of the solid is given by $S_{i}=\frac{V i_{S}}{V i_{T}}$.

$$
\phi_{T}=\phi_{1}+I_{1} \phi_{2}
$$

\section{Results}

For two spatial scales, the porosity and volumetric fraction were studied, in which the scale 1 is for plugs and the scale 2 for microplugues. The segmentation was performed through the PerGeos $\circledast$ version 1.7.0 software. Illustratively, Figure 2 below presents a $2 \mathrm{D}$ section of a microplug showing the spatial scale of the samples studied. The region of interest (ROI) analyzed is represented by the red square, in blue are the pores and in black the matrix. The segmented image is the basis for the next steps of three-dimensional rendering and parameters quantification.
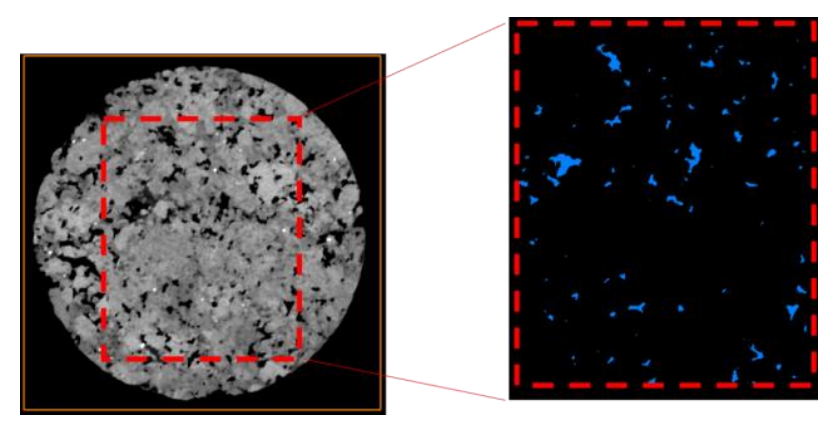

Figure 2 - 2D Section from one of microplugs analyzed.

From the multiscale composition model, porosity values were determined for each scale and total (in multiscale). Table 1 shows the results obtained from the multi-scalar composition model $\left(\phi_{\text {total }}\right)$ and the values for each scale $\left(\phi_{1}\right.$ and $\left.\phi_{2}\right)$. Each scale was acquired with a given spatial resolution, the spatial scale 1 (plugs) was imaged with the resolution of 18.52 microns and the scale 2 (microplugs) with resolution of 7 microns.

The Table 1 shows the contribution of each scale in the porous system as a whole, making the total porosity achieved close to the experimental one ( $\phi l a b)$. The contribution of the scale 2, for most of the samples analyzed, is somewhat small, suggesting the little presence of micropores.

The total porosity can be written in the form: 
Alyne D. Vidal'1 , Caroline H.Dias², Lizianne C.Medeiros², Inácio F. Borges², Josias José da Silva

Table 1 - Summary of the porosity values determined by the multiscale composition model and by laboratory test.

\begin{tabular}{|c|c|l|l|}
\hline $\boldsymbol{\phi}_{\mathbf{1}}$ & $\boldsymbol{\phi}_{\mathbf{2}}$ & $\boldsymbol{\phi}_{\text {total }}$ & $\boldsymbol{\phi}_{\text {lab }}$ \\
\hline 8,31 & 1 & 8,71 & 9,9 \\
\hline 3,58 & 0,35 & 4,88 & 12,8 \\
\hline 2,7 & 2,37 & 4,03 & 15,5 \\
\hline 7,04 & 4,4 & 8,80 & 10,5 \\
\hline 0,71 & 0,5 & 1,13 & 4,6 \\
\hline 14,4 & 1,3 & 15,36 & 11,4 \\
\hline 3,56 & 0,017 & 3,56 & 4,1 \\
\hline
\end{tabular}

It is emphasized again that due to the heterogeneous porous system of the samples in question, the possibility of using larger regions of interest will allow a better definition of the sizes of representative elementary volumes. In the Figure 3 it was possible to observe that the determination of the porosity through $\mu \mathrm{CT}$, in general, has a good correlation with the porosity measured in laboratory, however the digital porosity was smaller than the conventional porosity.

The most likely reason is the scale question and its representativeness of a heterogeneous sample, since the vugular porosity is predominant in these samples. Thus, in the assays, all the pores are measured and in digital, some pores may be outside the considered $\mathrm{ROI}$ for the porosity estimation, which results in lower values than those obtained in the laboratory tests. The contribution of each scale in the porous system as a whole made the total porosity achieved close to the experimental one.

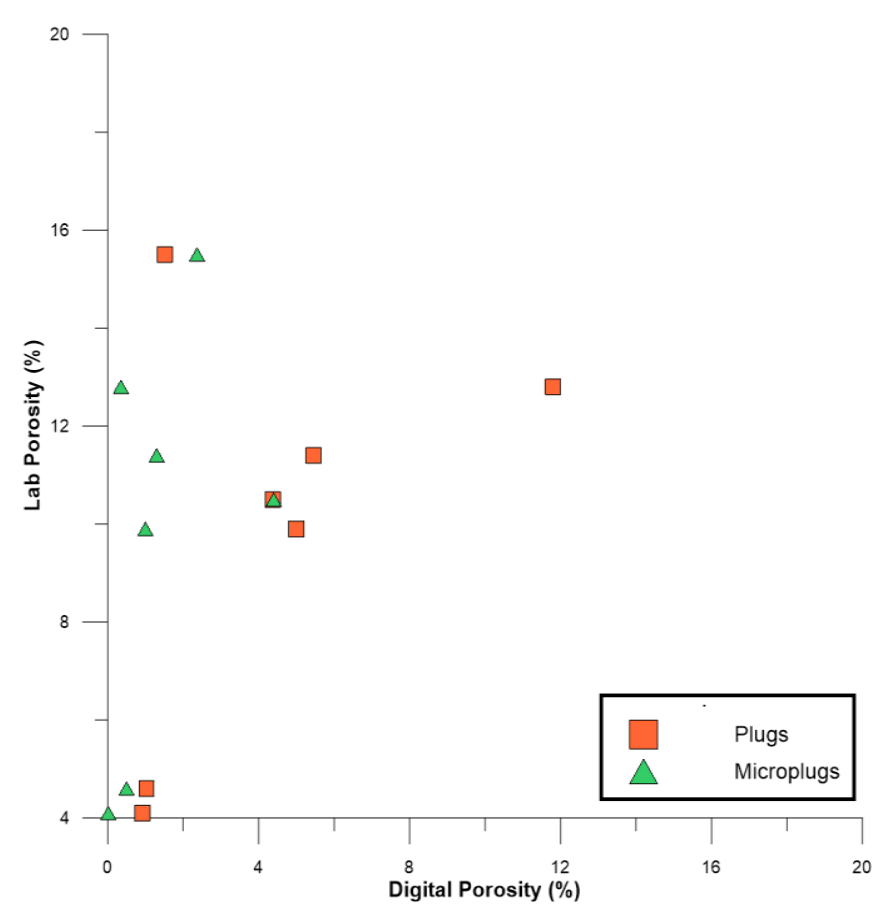

Figure 3 - Comparison of laboratory and digital data.

The results of the pore size distribution of the samples are shown in the graphs of Figures 4 and 5. These graphs reinforce the claim that the porous space of the carbonate is composed of pores of varying sizes.

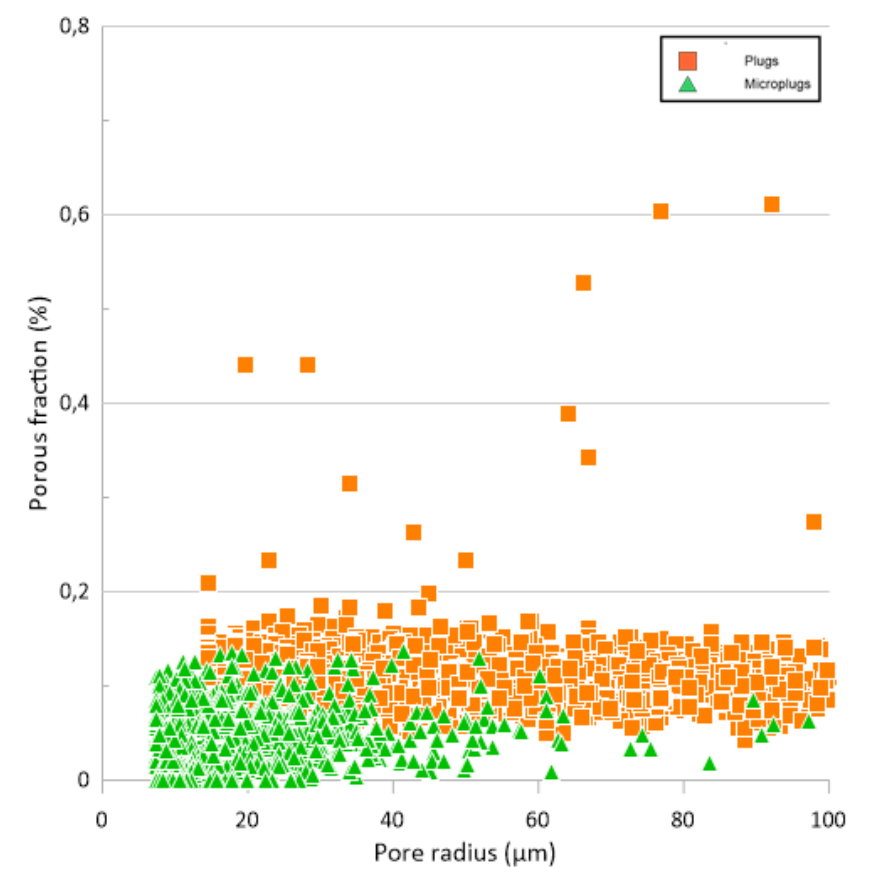

Figure 4 - Distribution of the intergranular pore size. 
Multiscale characterization of the porous system of carbonate rocks of the Brazilian Pre-salt

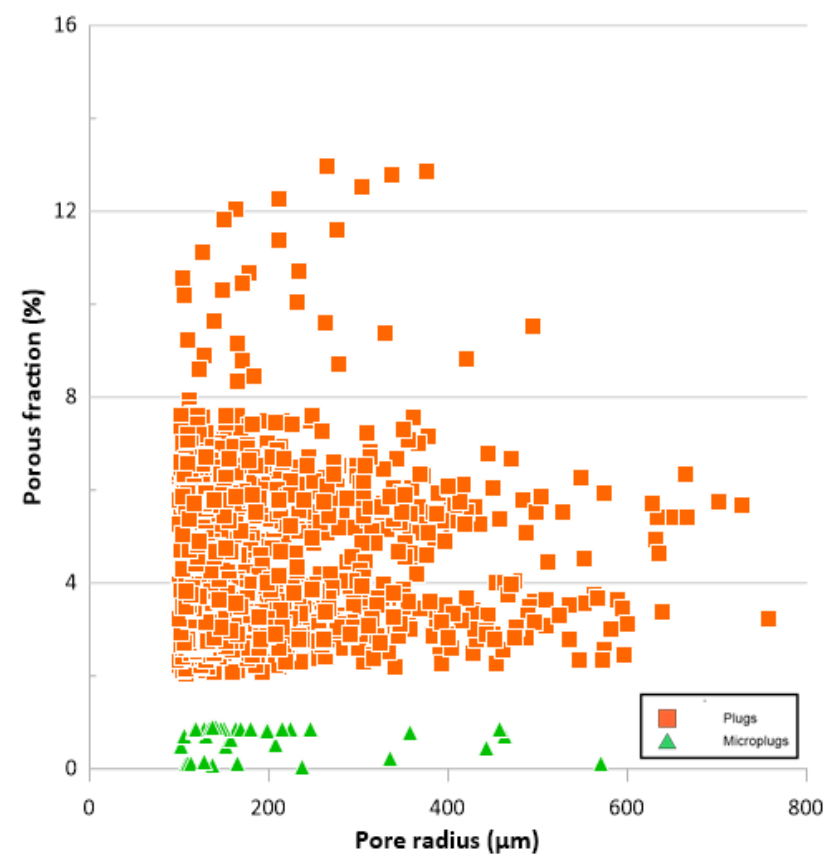

Figure 5 - Distribution of the vugular pore size.

\section{Conclusions}

The present work deals with the characterization of the multiscalar porous system of carbonate rocks through the processing and analysis of images acquired by $\mathrm{X}$ - ray microtomography.

The study of the analysis and composition of the different spatial scales showed the need for multiscalar treatment in the description of the porous carbonate system. The multiscale composition model allowed us to describe the complex system in order to characterize the various types of pores that constitute this type of rock. Due to the heterogeneous porous system of the samples in question, the possibility of using larger regions of interest will allow a better definition of the size of the representative volumes.

The multiscale composition was performed in order to consider two spatial scales, plugs and microplugs, presenting smaller digital porosity values than those measured in the laboratory. This fact may be an indication that the porous fraction, consisting of vugular pore size was not included in the volumes used in the digital simulation.

The pore size distribution showed the spatial variation of the pores. The distribution of the vugular pores showed that this kind of pore presents a greater influence than intergranular pores on the total porosity of the samples. Thus, in general, the dominant porosity in the samples was the vugular porosity, with high variability in relation to the pore sizes, thus showing that these samples have a heterogeneous porous system.
From these observations, it was noticed that the multiscalar treatment, that is, the study and analysis at different scales, allowed to describe the complex porous system, in order to understand much of the different pore sizes and porosities that constitute the carbonaceous rocks, being thus important in the process of characterization of the reservoirs composed by this type of rock.

The next step of this work is to include high definition tomography of core samples, where the presence of vugular porosity can be considered in the digital results.

\section{Acknowledgments}

This study was financed in part by the Coordenação de Aperfeiçoamento de Pessoal de Nível Superior- Brasil CNPQ - Finance Code 001.

We would also like to thank the Federal University of Rio de Janeiro for laboratory support and PETREC - Petroleum Research and Technology for accessing Pre Salt rock samples.

\section{References}

DOBRIN, M. B., 1976, Introduction to Geophysical Prospecting. USA, McGraw-Hill, 3 ed., 630p.

FERNANDES, C. P., 1994. Caracterização Morfológica de Espaços Porosos: Reconstrução Multiescala e Simulação de Processos de Invasão de Fluidos Não-molhantes. Phd Thesis. Federal University of Santa Catarina, Brasil.

PAPADOPOULOS, A.; WHITMORE, A. P.; WHITE, R. P.; MOONEY, S. J. e BIRD, N. R. A., 2009. Combining spatial resolutions in the multiscale analysis of soil pore-size distributions. Soil Science Society of América Journal, v. 8(1).

KUMAR, M.; HAN, D. Pore shape effect on elastic properties of carbonate rocks. SEG Technical Program Expanded Abstracts, p. 1477-1481, 2005.

LUCIA, F. J. Carbonate Reservoir Characterization: An Integral Approach, 2nd ed. Heidelberg: Springer Science, 337 p., 2007

MANTOVANI, I. F., 2013. Microtomografia e Nanotomografia de Raios X Aplicada à Caracterização Multiescalar de Sistemas Porosos Carbonáticos. Phd Thesis. Federal University of Santa Catarina, Brasil.

RAMAKRISHNAN, T. S.; RAMAMOORTHY, R.; FORDHAM, E.; SCHWARTZ, L.; HERRON, M.; SAITO, N. E RABAUTE, A. Method for interpretation carbonate reservoirs. SPE Annual Technical and Exhibition, New Orleans, SPE Paper 71704, 2001.

THOMAS, J. E., 2000, Velocidades Sísmicas. Universidade Petrobras, Rio de Janeiro, 132p. 